\section{HISTORY OF COSMOLOGY}

Le Système du Monde

Histoire des Doctrines Cosmologiques de Platon à Copernic, Tome 10. Par Prof. Pierre Duhem. Pp. 528. (Paris: Hermann, 1959.) n.p.

$\mathrm{T}$ HE great work of the late French historian of science, Pierre Duhem, on the history of cosmology from Plato to Copernicus, is now completed by the publication of Volumes 9 and 10. It will be remembered that only the first five volumes were published during the author's life in the years 191417. At the time there was no possibility of publishing the extant material for the remaining volumes, and it seemed that the historians of science would have to become resigned to the valuable work remaining a torso for ever. However, after the Second World War circumstances were ameliorated and so the rather rare situation could arise of the missing volumes appearing some forty years after the beginning of publication. On a previous occasion comment has been made upon the unavoidable drawback of the work becoming somewhat antiquated in the meantime. This, however, is only a slight disadvantage in comparison to the immense value to be attributed to Duhem's pioneering work, which forms the beginning of the modern interest in medieval natural science.

Of the new volumes, Volume 9 brings to completion the subject-matter of Volumes 7 and 8, mainly consisting of the Parisian physics of the fourteenth century. First, the theory of the tides is dealt with from William of Auvergne to Pierre d'Ailly; then follows the equilibrium of the Earth and the oceans, with an introduction to the idea of their centre of gravity of Greek and Arab commentators of Aristotle ; the origins of geology, including the theory of the small movements of the Earth. Hereafter the important question of the rotation of the Earth is tackled, the discussion of which was inaugurated by Duhem in 1909 in his epoch-making article on Oresme as a precursor of Copernicus, in the Revue Générale des Sciences. This article is substantially reproduced here and is supplemented by a discussion of the views of that other great figure of medieval physics, Jean Buridan. The author repeats his former conclusion that the daily rotation of the Earth was duly discussed in the Parisian school of the fourteenth century and that in particular Oresme deserves credit for his anticipation of the ideas of Copernicus on the Earth's daily rotation. In the final chapter of Volume 9 the problems of the plurality of worlds in connexion with the possibility of the vacuum and with the variability of gravity with the distance to the centre of the world are discussed.

In Volume 10 it becomes quite clear that it is not offered to us as a complete work, but only as a compilation of fragments in greater or lesser degree of perfection. The title of the whole of Volume 10 was not chosen by Duhem himself but was added by the editors, who hoped to sum up by it the principal contents of the volume. It announces a treatment of fifteenth-century cosmology and of the schools and universities in which it was developed. The decline of the University of Paris in the first half of the fifteenth century is dealt with rather elaborately, but the treatment of the subsequent developments leaves something to be desired. The German universities of that century receive full attention, but the English and Italian ones remain somewhat in the background; although Paul of Venice (Paolo Nicoletti) has an extensive chapter devoted to him. This is also the case of Nicolaus of Cusa, the German cardinal, whose ideas are expounded at length. Finally, there are chapters on the Viennese astronomers Peurbach and Regiomontanus and on the fourteenth-century humanists Petrarca and L. Bruni, which, however, are far from dealing exhaustively with the relation of humanism to medieval philosophy.

The treatment is everywhere extremely clear and interesting; one regrets that the work was not completed by its author. $\quad$ E. J. DiJKsterhuis

\section{RUSSIAN VIEW OF SPACE FLIGHT}

\section{Sputniks and After}

By Karl Gilzin. Translated from the Russian by Pauline Rose. Pp. $285+25$ photographs. (London : Macdonald and Co. (Publishers), Ltd., 1959.) 21s. net.

$\mathrm{K}$ ARL GILZIN, a lecturer at the Moscow Aviation Institute, gives here a popular account of the past, present and probable future of space flight. Brooding over the whole story is the spirit of Tsiolkovski, the 'father of astronautics', who foresaw in remarkable detail the techniques likely to prove most efficacious in space flight. Since British and American authors have scarcely done justice to this Russian pioneer, the eulogy in the present book will do no harm. It also serves to remind us how the Russians have created, around the name of Tsiolkovski as patron saint, a mystique of space flight which is unparalleled in the Western world : it is no accident that experiments with animals, a necessary prelude to manned space travel, have figured so largely in the Soviet rocket and satellite programmes, or that Sputnik 1 was launched within a month of the centenary of Tsiolkovski's birth.

The subject-matter of the book can be divided into three sections, past, present and future. The first section expounds the principles of space flight and traces the development of rockets and other power units in fair detail, though with a pro-Russian bias : Tsiolkovski figures in the history of the gas-turbine engine, but not Whittle. The second section, covering present developments, though it includes a good chapter on the atmosphere, is disappointing in detail : there is no new information on the Sputniks, and the meagre report of the results obtained from them (which appears to date from mid-1958) is, a little surprisingly, based largely on British radio observations reported in Nature. The last section is an excellent preview of space flight, which ends with an imaginary but realistic excursion to the Moon by a party of school-children.

The material is presented in an easy, expert manner and the book is well illustrated and technically reliable. There are a number of lapses and inconsistencies, however: for example, the rocket of Sputnik 1 is on p. 117 said to have completed its 900th circuit of the Earth on December 2, 1957, when it really came down on the previous day, as is implied on p. 131 ; on p. 139 Jodrell Bank is described as an Irish radio observatory, a peccadillo startling to parochial ears; and the last paragraph on p. 102 does not follow from the one before.

The translation is competent, but too overloaded with abstract nouns to be called graceful, and the phraseology sometimes conflicts with established usage : 'thrust' sometimes masquerades as 'traction', and 'solid fuel' as 'dry fuel'. D. G. KING-HeLE 